man, a former representative of the Environmental Defense Fund who has long been active in seeking more public debate and stricter controls on recombinant DNA research.

While those legislative developments were taking place last week, the Academy's public meeting was in full, and sometimes noisy, swing at the other end of the Mall. Though the meeting essentially covered ground which has already been well trodden in college campuses and city halls around the country, it nevertheless generated considerable national attention and not a little friction.

Most of the high-temperature exchanges took place at the opening session, when a group called the Peoples' Business Commission (a reincarnation of the Peoples' Bicentennial Commission) staged a series of disruptions. Jeremy Rifkin, a spokesman for the group, was invited to address the meeting to air his grievances, and as he did so several of his supporters unfurled banners proclaiming their opposition to the research. Rifkin harangued the organisers of the meeting, claiming that the fact that it was supported financially by several drug companies rendered it suspect. In particular, Rifkin claimed that because the agenda was dominated by sessions concerned with potential health hazards from recombinant DNA research, it missed the central question of how the long-term implications of the research should be dealt with. Genetic engineering, he opined, is "the most important issue that society has to grapple with", and he told the researchers present that "you can't hide from the facts any more than the physicists who split the atom".

Although the interruptions and objections formed just a part of the meeting, Rifkin's objections did surface later in rather more subtle form, from speakers such as Jon Beckwith of Harvard, who noted that though there are still some barriers left to introducing genes into human cells, "these goals are not at all inconceivable and they may be achieved very rapidly". Beckwith announced that he has renounced use of recombinant DNA techniques, because "I do not wish to contribute to the development of a technology which I believe will have profound and harmful effects on this society".

Other speakers noted that one of the potential benefits often claimed for recombinant DNA is to help understand the causes of cancer. Such observations put the debate onto a different level from discussion of potential health hazards, and they could be much more difficult for scientists to grapple with.

\section{Sweet sorrow}

AFTER more than six years of uncertainty, the Food and Drug Administration (FDA) last week decided to ban the artificial sweetener saccharin from general use in the United States. The action, which was prompted by clear evidence that the sweetener can cause bladder cancer in rats when fed to them in large quantities, immediately prompted shrill protests from the food industry, and it is sure to touch off a new round of attacks on the so-called Delaney Amendment which bans use of any food additive found to cause cancer in animals.

The evidence which finally sounded the death knell for saccharin came from a long-term feeding study sponsored by the Canadian government, preliminary results of which were made available to FDA officials on 7 March. Two days later, FDA and the Canadian Department of Health and Welfare announced that the sweetener would be banned both in Canada and the United States.

The full results of the study have not been published, but according to a summary made available by FDA, it turned up the following results. Out of 50 male and 50 female rats fed a diet containing $5 \%$ saccharin throughout their lives, three males and no females developed malignant bladder tumours. In addition, 50 male and 50 female offspring of those rats were also fed diets loaded with saccharin. The cancer incidence among them was more pronounced: 12 male and 2 female animals developed bladder tumours. Thus, 17 out of 200 test rats developed cancer compared with 2 out of 100 in a control group.

Until the full results are published, it is difficult to tell how good the study was. It has, however, long been regarded as the best test of saccharin yet undertaken, and FDA officials have been eagerly awaiting the results in the expectation that the study would finally settle the question of whether saccharin is or is not a carcinogen. They were impressed. The tests, according to Sherwin Gardner, the Acting FDA Commissioner, "show unequivocally that this substance can produce malignant bladder tumours in rats".

It has sometimes been suggested that the carcinogenic potential of saccharin may be caused not by the sweetener but by an impurity, orthotoluenesulphonamide (OTS). The Canadian tests, however, included a separate study of OTS and no carcinogenic effects were discovered.
FDA was therefore left with no choice but to ban saccharin from the market, an action which Gardner suggested was "based on science and on the requirements of Federal law". FDA hopes to publish details of the ban within a month, but it will allow those products already manufactured to be sold.

The ban could have considerable economic impact since saccharin is now the only artificial sweetener on the market in the United States. Cyclamates were banned in 1969, following evidence that they also cause bladder cancer in rats. And another sweetener, aspartame, was due to be approved by FDA a couple of years ago but approval was withdrawn following a discovery that the manufacturer of the substance submitted misleading test data. Once saccharin is removed from the market, there will be no non-nutritive sweetener for use by the burgeoning diet food industry. Some 5 million pounds of saccharin is now used in the United States, about three quarters of which goes into soda pop.

FDA's regulation of saccharin came under blistering attack last year in a study published by the General Accounting Office (GAO), an investigatory agency of the Congress. Noting that doubts about the safety of saccharin were raised in the early 1970 s, particularly after a study published in 1971 indicated that the sweetener may be a potential carcinogen, GAO suggested that "extended use of a food additive, such as saccharin, whose safety has not been established and for which a carcinogenic potential has been raised, could expose the public to unnecessary risk".

FDA did, however, take some action against saccharin in 1972. It limited the amount of the sweetener which could be added to food and drink, and ordered that the substance should be used only in special dietary products. The latter requirement hasn't been rigorously enforced, however, for use of the sweetener has mushroomed, diet sodas are heavily promoted for general use, and saccharin is now found in products like toothpaste and pancake syrup.

With such a large volume of sales to protect, the food industry is expected to appeal the ban, through the courts if necessary. Some nutritionists are warning of the health consequences of an increased consumption of sugar.

Colin Norman 